\title{
Factors Related to the Satisfaction with Pregnancy and Childbirth in Japanese Mothers Residing in the UK
}

\author{
Motomi Otsuka $^{1,2, *}$, Hiroya Matsuo ${ }^{1}$ \\ ${ }^{1}$ Department of International Health, Kobe University Graduate School of Health Sciences, Japan \\ ${ }^{2}$ Department of Nursing, Okayama University Graduate School of Health Sciences, Japan
}

Received September 1, 2019; Revised November 11, 2019; Accepted November 20, 2019

Copyright $(2019$ by authors, all rights reserved. Authors agree that this article remains permanently open access under the terms of the Creative Commons Attribution License 4.0 International License

\begin{abstract}
This study aimed to investigate whether medical care and health services provided during pregnancy and childbirth influence the satisfaction with pregnancy and childbirth in Japanese mothers residing in the UK. The participants $(\mathrm{N}=41)$ were members of the Japanese child-rearing group in London, UK, who had experienced antenatal to postpartum care in the UK. The questionnaire contained the background of the Japanese mothers residing in the UK, pregnancy and childbirth, difficulties in the UK's hospital visiting, satisfaction with health care service, adviser and evaluation scales for pregnancy and childbirth. Almost all participants consulted their Japanese friends residing in the UK, or husbands/partners, and they obtained the information on pregnancy and childbirth from the Internet written in Japanese and Japanese friends who were living and had experienced childbirth in the UK. Approximately $80 \%$ of Japanese mothers were satisfied with pre-natal clinic and childbirth in the UK. They were satisfied with the health care provided by midwife and home visiting service after discharge from the hospital. The satisfaction with pre-natal clinics in Japanese mother residing was related to intercultural understanding, while the satisfaction with childbirth was related to understanding of medical system, cross-cultural understanding and trust of medical stuff.
\end{abstract}

Keywords Japanese Mothers, UK, Pregnancy, Childbirth, Midwifery Care

\section{Introduction}

The number of Japanese residents abroad has increased yearly with the globalization of society such as working abroad and international marriage, with the UK having the sixth largest increase after the United States, China, Australia, Thailand, and Canada [1].The Annual Report of
Statistics on Japanese Nationals Overseas by the Ministry of Foreign Affairs demonstrates that the number of long-term stay Japanese residents abroad was 1,351,970 in 2017 , which increased to approximately 1.1 percent from the previous year and includes younger generation[1]. These have contributed to the increased number of pregnancy and childbirth in Japanese residents abroad. The overseas birth of Japanese is reported to be 13,801 , while that in Japan was 941,000 [2].

It was reported that Japanese mothers abroad have experienced embarrassment because of differences in medical and health systems and language barrier. Taniguchi et al. indicated that Japanese residents in Hawaii may have experienced anxiety during perinatal to childbirth because of differences in culture and medical system between Hawaii in USA and Japan [3] [4] [5]. Orito et al. reported that Japanese mothers who had given birth in South East Asia experienced anxiety because of language barrier and the differences in the level of medical care[6].

However, studies demonstrating whether medical care and health services during pregnancy and childbirth influence the outcome or the satisfaction in Japanese mothers abroad are insufficient. Therefore, we conducted the present study to examine the medical care and health services that were provided during pregnancy and childbirth to Japanese mothers residing in the UK and whether they influence the satisfaction with pregnancy and childbirth.

\section{Subjects and Methods}

\subsection{Subjects}

Participants included 41 Japanese mothers residing in London, the UK who have experienced pregnancy and childbirth, and child-rearing younger than 5 years old. The 
nationality of the Japanese mothers' husbands and partners were not considered in this study. Exclusion criteria was not defined. The purpose of this study was explained to a representative of the Japanese child-rearing group, NAKAYOSHI-KAI (NAKAYOSHI-KAI is Japanese child-rearing self-help group in London) in the UK, who eventually approved this study. Furthermore, we explained the purpose of this study to Japanese mothers who participated at a child-rearing event of NAKAYOSHI-KAI held in London and distributed self-reported questionnaire using the postal method. After child-rearing meeting, they filled the questionnaire, and mailed the questionnaire afterwards in the post. A total of 41 participants were collected (collection rate was $75.9 \%$ ).

\subsection{Methods}

\subsubsection{Questionnaire}

The questionnaire contained the subjects' background (age, birthing age, academic background, parity, reason for staying in the UK, house fold, partners' nationality, communication level in English) and Japanese mother's pregnancy and childbirth (a company person pre-natal clinics, weight gain during pregnancy, obstetrical disorders, birth places, mode of delivery, childbirth with partner, utilization of Japanese mothers' self-help group, nutrition intake during pregnancy, the control of weight during pregnancy, reason for childbirth in the UK, length of hospitalization, next childbirth place, wish of a Japanese maternity custom and enforcement of Japanese maternity custom about wearing FUKUTAI (abdominal belt) and keeping the umbilical cord, and health care and its satisfaction). Health care on the general practitioner (GP) and National Health Service (NHS) were evaluated as either "good" or "bad." Another health care on perinatal clinics and childbirth were evaluated according to the five-grade system: "very satisfied," "satisfied," "neither," "dissatisfied," and "very dissatisfied." "very satisfied," and "satisfied" were grouped as "satisfaction" and "neither," and "dissatisfied," and "very dissatisfied" were grouped as "dissatisfaction." Regarding the evaluation on the experience of pregnancy and childbirth, we investigated the difficulty in accessing the UK's hospital and the advisers and the source of information during pregnancy, childbirth, and postpartum and satisfaction with health care service. The difficulty was evaluated according to the five-grade system: "not troubled," "slightly troubled," and "troubled." "Not troubled" was grouped as "no difficulty," and "slightly troubled," and "troubled" were grouped as "difficulty." The satisfaction was evaluated according to the five-grade system: "very satisfied," "satisfied," "neither," "dissatisfied," and "very dissatisfied." "very satisfied," and "satisfied" were grouped as "satisfaction" and "neither," and "dissatisfied," and "very dissatisfied" were grouped as "dissatisfaction."

\subsubsection{Evaluation of Maternal Consciousness and Transcultural Understanding}
(1) Self-evaluation childbirth experience scale (short version)

Self-evaluation childbirth experience scale (short version), which measures 18 activities divided into 3 categories, labor coping, trust to medical staff, and physiological childbirth progress[7][8], is used to evaluate childbirth experience. This scale measures satisfaction with childbirth, it shows that the high score means satisfaction with childbirth. Each item is scored from 1 to 5 , ranging from total dependence to independence, and the total score ranges from 18 points (full dependence) to 90 points (complete independence), and the lower the score, the worse is the satisfaction level of the mothers' childbirth experience. We calculated the average of the subcategories self-evaluation childbirth experience scale (short version) and subcategories and divided them into two groups, the high experience group (high labor coping, high trust medical staff and high physiological progress; higher than the average) and the low experience group (low labor coping, low trust medical staff and low physiological progress; lower than the average), in this study.

\section{(2) Maternal consciousness scale}

To confirm mother's acceptance of childbirth progress, we used the maternal consciousness scale[9][10]. The scale measures 12 activities divided into 2 categories that measure the positive feeling and the negative feeling. This scale measures maternal consciousness for Japanese mother, it shows that the high score means positive maternal consciousness. Each item is scored from 1 to 4 , ranging from total dependence to independence, and the total score ranges from 12 points (full dependence) to 48 points (complete independence), and the higher the score, the better the acceptance level of the mothers' role. We calculated the average of the total score of maternal consciousness scale, and we divided them into two acceptance groups, the high motherhood group (positive; higher than the average) and the low motherhood group (negative; lower than the average), in this study.

\section{(3) Couple-related scale}

Couple-related scale[11][12] is used to measure couple relationship, which measures 6 activities and scored from 1 to 4 , ranging from total dependence to independence, and the total score ranges from 6 points (full dependence) to 24 points (complete independence), and the higher the score, the better is the couple relationship. This scale measures couple relationship for Japanese mother with husband/partner, it shows that the high score means good couple relationship. We divided the couple relationship into two groups, the high relationship group (higher than the average) and the low relationship group (lower than the average), in this study. 
(4) Cross-cultural understanding scale

Cross-cultural understanding scale, comprising 45 activities, is used to measure cross-cultural understanding[13][14]. In this study, we extracted 8 items related to this investigation. This scale measures cross-cultural understanding for Japanese mother, it shows that the high score means excellent cross-cultural understanding. Each item is scored from 1 to 4, ranging from total dependence to independence, and the total score ranges from 8 points (total dependence) to 32 points (complete in dependence), and the higher the score, the better is the acceptance level of cross-cultural understanding scale. We divided the cross-cultural understanding scale into two acceptance groups, the high understanding group (higher than the average) and the low understanding group (lower than the average), in this study.

\section{Statistical Analyses}

Data were entered in the Microsoft Excel and imported into the International Business Machines Corporation Statistical Package for the Social Sciences version 25 for analysis. Chi-squared test comparisons was used to assess the differences with $\mathrm{P}$ value $<0.05$ considered statistically significant.

\section{Ethical Considerations}

This study was approved by the Ethical Committee of Kobe University Graduate School of Health Sciences (No.436). Along with the questionnaire, we provided participants with a letter stating the purpose, methods, risks, and benefits of this study; voluntary participation, confidentiality and privacy; and the right to refuse participation. They were also informed that they would not be able to withdraw after submitting their questionnaire in the return envelope.

\section{Results}

\subsection{Subjects' Background (Table 1)}

Valid response was obtained in 41 subjects, who consisted of 28 primiparas (68.3\%) and 13 multiparas (31.7\%). The mean age was $36.6 \pm 4.2$ years (range, 27 to 46 years). Birthing age was $35.0 \pm 4.0$ years (range, 27 to 46 years). Regarding academic background, the percentages of graduate school, university, junior college, and college were $19.5 \%, 46.3 \%, 14.6 \%$, and $19.5 \%$, respectively. Reasons for staying in the UK were marriage, partner's overseas, partners' posted overseas, mother's overseas, mother's posted overseas, and others $(55.8 \%$, $0 \%, 20.9 \%, 4.7 \%, 7.0 \%$, and $11.6 \%$, respectively). Regarding house fold, the percentages of husband/partner and child were $100 \%$ and $31.7 \%$, respectively. According to the partners' nationality, the percentages of Japan, the UK, other countries, and nonresponse were $24.4 \%, 36.6 \%$, $36.6 \%$, and $2.4 \%$, respectively.

With regard to the ability of communication level in English, the percentages of daily conversation were "92.7\% (no problem)," "4.9\% (smattering)," and " $2.4 \%$ (no idea)," while the percentages of medical level conversation were " $70 \%$ (no problem)", " $26.8 \%$ (smattering)," " $2.4 \%$ (no idea)," and " $2.4 \%$ (nonresponse)."

Table 1. Background of subjects ( $\mathrm{N}=41)$

\begin{tabular}{|c|c|c|c|c|c|}
\hline & Age (Y) & $36.6 \pm 4.2(27-46)$ & & & \\
\hline & Birthing age (Y) & $35.0 \pm 4.0(27-46)$ & & & \\
\hline \multicolumn{6}{|c|}{ Academic background } \\
\hline 1 & College & $8(19.5 \%)$ & & & \\
\hline 2 & Junior college & $6(14.6 \%)$ & & & \\
\hline 3 & University & $19(46.3 \%)$ & & & \\
\hline 4 & Graduate school & $8(19.5 \%)$ & & & \\
\hline \multirow{3}{*}{\multicolumn{2}{|c|}{$\begin{array}{c}\text { Reason for staying in the } \\
\text { UK }\end{array}$}} & Primipara $28(68.3 \%)$ & Multipara 13(31.7\%) & & \\
\hline & & Marriage 2(55.8\%) & $\begin{array}{c}\text { Partners' overseas } \\
0(0 \%)\end{array}$ & \multicolumn{2}{|l|}{$\begin{array}{c}\text { Partners' posted overseas } \\
9(20.9 \%)\end{array}$} \\
\hline & & $\begin{array}{c}\text { Mother's overseas } \\
2(4.7 \%)\end{array}$ & $\begin{array}{c}\text { Mother's posted } \\
\text { overseas } \\
3(7.0 \%) \\
\end{array}$ & Others $5(11.6 \%)$ & \\
\hline & House fold & $\begin{array}{c}\text { Husband/partner } \\
41(100 \%)\end{array}$ & $\begin{array}{c}\text { Child } \\
13(31.7 \%)\end{array}$ & & \\
\hline & Partners' nationality & Japan 10(24.4\%) & The UK 15(36.6\%) & $\begin{array}{c}\text { Other countries } \\
15(36.6 \%)\end{array}$ & Nonresponse $1(2.4 \%)$ \\
\hline \multicolumn{6}{|c|}{ Communication level in English } \\
\hline 1 & Daily conversation & Not hinder 38(92.7\%) & Smattering 2(4.9\%) & No idea $1(2.4 \%)$ & \\
\hline 2 & $\begin{array}{l}\text { Medical level } \\
\text { conversation }\end{array}$ & Not hinder $28(70.0 \%)$ & Smattering $11(26.8 \%)$ & No idea $1(2.4 \%)$ & Nonresponse $1(2.4 \%)$ \\
\hline
\end{tabular}




\subsection{Japanese Mothers' Pregnancy and Childbirth (Table 2)}

Regarding a company person with pre-natal clinics, the percentages of "no" and "yes" were $26.8 \%$ and $73.2 \%$, respectively. The percentages of "yes with husband or partner" and "yes with others" were $73.2 \%$ and $2.2 \%$, respectively. Weight gain during pregnancy was $10.3 \pm 3.0$ $\mathrm{kg}$ (range, $5.0-17.0 \mathrm{~kg}$ ). The percentages of obstetrical disorders were $24.4 \%$ for "yes" and $87.8 \%$ for "no." Childbirth places were NHS labor ward (58.5\%), NHS birth center $(31.7 \%)$, home birth $(2.4 \%)$, private $(4.9 \%)$, and nonresponse $(2.4 \%)$. The modes of delivery were "normal birth (23.5\%)," "epidural birth (23.5\%)," "induction of labor (11.8\%)," "water birth (11.8\%)," "vacuum/forceps (13.7\%)," and "caesarean section $(15.7 \%)$ " by multiple answer. According to childbirth with partner, the percentages of "yes" and "no" were $92.7 \%$ and $2.4 \%$, respectively.

Regarding the utilization of Japanese mother's self-help group, the percentages of "from pregnancy period," "after childbirth," and "no participation" were $17.0 \%, 53.7 \%$, and $29.3 \%$, respectively. With regard to nutrition intake during pregnancy, the percentages of "not troubled," "mostly Japanese foods," "not worry," and "nonresponse" were $39.0 \%, 22.0 \%, 34.1 \%$, and $4.9 \%$, respectively. Regarding on the perception control of weight gain during pregnancy, the percentages of "difficult" and "easy" were $12.2 \%$ and $87.8 \%$, respectively. Regarding reason for childbirth in the UK which for mothers answered, the percentages of "stay with partner," "the UK's childbirth system," "medical care level," "cost," and "others" were $66.0 \%, 10.6 \%, 0 \%, 6.4 \%$, and $17.0 \%$, respectively, by multiple answer. Regarding the perception of hospitalization length, the percentages of "proper," "short," "long," and "nonresponse" were $65.9 \%, 31.7 \%, 0 \%$, and $2.4 \%$, respectively. Regarding next childbirth place, "the UK", "Japan" and "others" were $68.2 \%, 9.8 \%$ and $12.8 \%$, respectively. Regarding wish of a Japanese maternity custom, for FUKUTAI (abdominal belt), the percentages of "wished," "not wished," and "nonresponse" were $36.6 \%, 46.3 \%$, and $17.1 \%$, respectively. Additionally, regarding keeping the umbilical cord, the percentages of "wished," "not wished," and "nonresponse" were 70.7\%, $22.0 \%$, and $7.3 \%$, respectively. Regarding enforcement of Japanese maternity custom, FUKUTAI (abdominal belt), the percentage of "did," "did not," and "nonresponse" were $29.3 \%, 68.3 \%$, and $2.4 \%$, respectively, while on keeping of umbilical cord, the percentage of "did," "did not," and "nonresponse" were $63.4 \%, 36.5 \%$, and $2.4 \%$, respectively. Regarding the satisfaction with GP and NHS in subjects, in GP, the percentages of "good" and "bad" were $43.8 \%$ and $56.2 \%$, respectively, while on NHS, the percentages of "good" and "bad" were $68.0 \%$ and $32.0 \%$, respectively. With respect to health care during perinatal period and its satisfaction, in pre-natal clinics, the percentages of "very satisfied," "satisfied," "neither," "dissatisfied," and "very dissatisfied" were 24.4\%, 53.7\%, $14.6 \%, 4.9 \%$, and $2.4 \%$, respectively. The percentage in the pre-natal clinics satisfaction group was $78.1 \%$, while that of the dissatisfaction group was $21.9 \%$. On the contrary, the percentages of "very satisfied," "satisfied," "neither," "dissatisfied," and "very dissatisfied" on childbirth were $34.1 \%, 43.9 \%, 12.2 \%, 2.4 \%$, and $7.3 \%$, respectively. The percentage in the childbirth satisfaction group was $78.0 \%$, while that of the dissatisfaction group was $22.0 \%$. 
Table 2. Japanese mothers' pregnancy and childbirth $(\mathrm{N}=41)$

\begin{tabular}{|c|c|c|c|c|c|c|}
\hline \multirow{2}{*}{\multicolumn{2}{|c|}{$\begin{array}{c}\text { A companied person } \\
\text { perinatal clinic(M/A) } \\
\begin{array}{c}\text { Weight gain during } \\
\text { pregnancy }(\mathrm{kg})\end{array}\end{array}$}} & \multirow{2}{*}{$\begin{array}{c}\text { No } 11(26.8 \%) \\
10.0 \pm 3.0(5.0 \sim 17.0)\end{array}$} & \multicolumn{4}{|c|}{$\begin{array}{c}\text { Yes 30(73.2\%) } \\
\text { Husband or partner 30/41(73.2\%) Others 1/41(2.2\%) }\end{array}$} \\
\hline & & & & & & \\
\hline & bstetrical disorder & Yes $10(24.4 \%)$ & No $31(87.8 \%)$ & & & \\
\hline & Childbirth place & $\begin{array}{l}\text { NHS } \cdot \text { Labor ward } \\
24(58.5 \%)\end{array}$ & $\begin{array}{l}\text { NHS } \cdot \text { Birth } \\
\text { center } 13(31.7 \%)\end{array}$ & $\begin{array}{l}\text { Home birth } \\
1(2.4 \%)\end{array}$ & $\begin{array}{l}\text { Private } \\
2(4.9 \%)\end{array}$ & $\begin{array}{c}\text { Nonresponse } \\
1(2.4 \%)\end{array}$ \\
\hline \multirow{2}{*}{\multicolumn{2}{|c|}{ Mode of delivery (M/A) }} & Normal $12(23.5 \%)$ & $\begin{array}{c}\text { Epidural } \\
12(23.5 \%)\end{array}$ & $\begin{array}{l}\text { Induction of labor } \\
\quad 6(11.8 \%)\end{array}$ & $\begin{array}{l}\text { Water birth } \\
6(11.8 \%)\end{array}$ & $\begin{array}{c}\text { Vacuum/forceps } \\
7(13.7 \%)\end{array}$ \\
\hline & & $\mathrm{C} / \mathrm{S} 8(15.7 \%)$ & & & & \\
\hline \multicolumn{2}{|c|}{ Childbirth with partner } & Yes $38(92.7 \%)$ & No $1(2.4 \%)$ & \multicolumn{2}{|c|}{ Nonresponse $2(4.9 \%)$} & \\
\hline \multicolumn{2}{|c|}{ Japanese mothers' group } & \multicolumn{2}{|c|}{ From pregnancy period $7(17.0 \%)$} & $\begin{array}{l}\text { After childbirth } \\
22(53.7 \%)\end{array}$ & $\begin{array}{c}\text { No participation } \\
12(29.3 \%)\end{array}$ & \\
\hline \multirow{2}{*}{\multicolumn{2}{|c|}{$\begin{array}{l}\text { Nutrition intake } \\
\begin{array}{c}\text { The control of weight } \\
\text { gain }\end{array}\end{array}$}} & $\begin{array}{c}\text { Not troubled } \\
16(39.0 \%)\end{array}$ & \multicolumn{2}{|c|}{ Mostly Japanese foods $9(22.0 \%)$} & $\begin{array}{l}\text { Not worry } \\
14(34.1 \%)\end{array}$ & $\begin{array}{l}\text { Nonresponse } \\
2(4.9 \%)\end{array}$ \\
\hline & & Difficult 5(12.2\%) & Easy $36(87.8 \%)$ & & & \\
\hline \multirow{2}{*}{\multicolumn{2}{|c|}{$\begin{array}{l}\text { Reason for childbirth } \\
\text { (M/A) }\end{array}$}} & $\begin{array}{l}\text { Stay with partner } \\
31(66.0 \%)\end{array}$ & \multicolumn{2}{|c|}{ The UK's childbirth system 5(10.6\%) } & $\begin{array}{c}\text { Medical care level } \\
0(0 \%)\end{array}$ & Cost $3(6.4 \%)$ \\
\hline & & Others $8(17.0 \%)$ & & & & \\
\hline \multicolumn{2}{|c|}{ Length of hospitalization } & Proper $27(65.9 \%)$ & Short $13(31.7 \%)$ & Long $0(0 \%)$ & \multicolumn{2}{|c|}{ Nonresponse $1(2.4 \%)$} \\
\hline \multicolumn{2}{|r|}{ Next childbirth place } & UK $28(68.2 \%)$ & Japan $4(9.8 \%)$ & Others $5(12.8 \%)$ & \multicolumn{2}{|c|}{ Nonresponse $4(9.8 \%)$} \\
\hline \multicolumn{7}{|c|}{ Wish of Japanese maternity custom } \\
\hline 1 & $\begin{array}{c}\text { FUKUTAI } \\
\text { (maternity girdle) }\end{array}$ & Wished $15(36.6 \%)$ & $\begin{array}{l}\text { Not wished } \\
19(46.3 \%)\end{array}$ & $\begin{array}{c}\text { Nonresponse } \\
7(17.1 \%)\end{array}$ & & \\
\hline 2 & $\begin{array}{l}\text { Keeping of umbilical } \\
\text { cord }\end{array}$ & Wished 29(70.7\%) & $\begin{array}{l}\text { Not wished } \\
9(22.0 \%)\end{array}$ & $\begin{array}{c}\text { Nonresponse } \\
3(7.3 \%)\end{array}$ & & \\
\hline \multicolumn{7}{|c|}{ Enforcement of Japanese maternity custom } \\
\hline 1 & $\begin{array}{c}\text { FUKUTAI } \\
\text { (maternity girdle) }\end{array}$ & Did 12(29.3\%) & $\begin{array}{l}\text { Did not do it } \\
28(68.3 \%)\end{array}$ & $\begin{array}{c}\text { Nonresponse } \\
1(2.4 \%)\end{array}$ & & \\
\hline 2 & $\begin{array}{l}\text { Keeping of umbilical } \\
\text { cord }\end{array}$ & $\operatorname{Did} 26(63.4 \%)$ & $\begin{array}{c}\text { Did not do it } \\
15(36.5 \%)\end{array}$ & $\begin{array}{c}\text { Nonresponse } \\
1(2.4 \%)\end{array}$ & & \\
\hline \multicolumn{7}{|c|}{ Health care and its satisfaction } \\
\hline 1 & GP(M/A) & Good 21(43.8\%) & $\operatorname{Bad} 22(56.2 \%)$ & & & \\
\hline 2 & NHS (M/A) & Good 34(68.0\%) & $\operatorname{Bad} 16(32.0 \%)$ & & & \\
\hline 3 & Pre-natal clinics & $\begin{array}{c}\text { Very satisfied } \\
10(24.4 \%)\end{array}$ & $\begin{array}{c}\text { Satisfied } \\
22(53.7 \%)\end{array}$ & Neither $6(14.6 \%)$ & $\begin{array}{c}\text { Dissatisfied } \\
2(4.9 \%)\end{array}$ & $\begin{array}{c}\text { Very dissatisfied } \\
1(2.4 \%)\end{array}$ \\
\hline 4 & Childbirth & $\begin{array}{c}\text { Very satisfied } \\
14(34.1 \%)\end{array}$ & $\begin{array}{c}\text { Satisfied } \\
18(43.9 \%)\end{array}$ & Neither $5(12.2 \%)$ & $\begin{array}{c}\text { Dissatisfied } \\
1(2.4 \%)\end{array}$ & $\begin{array}{c}\text { Very dissatisfied } \\
3(7.3 \%)\end{array}$ \\
\hline
\end{tabular}

\subsection{Difficulties in the UK's Hospital Visiting (Table 3)}

Regarding difficulties they felt at visiting the hospitals in the UK, as communication at the hospital, the percentages of "not troubled," "slightly troubled," and "troubled" on communication were $63.4 \%, 31.7 \%$, and $4.9 \%$, respectively. Regarding they felt about difficult medical administration system, the percentages of "not troubled," "slightly troubled," and "troubled" were $65.9 \%$, $29.3 \%$, and $4.9 \%$, respectively. With regard to intercultural understanding at the hospital, the percentages of "not troubled," "slightly troubled," and "troubled" were $70.7 \%, 26.8 \%$, and $2.4 \%$, respectively. Regarding economics (medical expense) at the hospital, the percentages of "not troubled," and "slightly troubled" were $97.6 \%$ and $2.4 \%$, respectively. 
Table 3. Difficulty in the UK's hospital visiting $(\mathrm{N}=41)$

\begin{tabular}{|c|c|c|c|}
\hline Communication at the hospital & Not troubled 26(63.4\%) & Slightly troubled 13(31.7\%) & Troubled 2(4.9\%) \\
\hline Medical administration system & Not troubled 27(65.9\%) & Slightly troubled 12(29.3\%) & Troubled 2(4.9\%) \\
\hline Intercultural understanding at the hospital & Not troubled 27(65.9\%) & Slightly troubled $11(26.8 \%)$ & Troubled $1(2.4 \%)$ \\
\hline Economics(medical expense) at the hospital & Not troubled $40(97.6 \%)$ & Slightly troubled $1(2.4 \%)$ & Troubled $0(0 \%)$ \\
\hline
\end{tabular}

Table 4. Satisfaction of health care service $(\mathrm{n}=41)$

\begin{tabular}{|c|c|c|c|c|c|c|}
\hline Question & $\begin{array}{l}\text { Very } \\
\text { satisfied } \\
\mathrm{n}(\%)\end{array}$ & $\begin{array}{l}\text { Satisfied } \\
\mathrm{n}(\%)\end{array}$ & $\begin{array}{l}\text { Neither } \\
\mathrm{n}(\%)\end{array}$ & $\begin{array}{l}\text { Dissatisfied } \\
\mathrm{n}(\%)\end{array}$ & $\begin{array}{c}\text { Very } \\
\text { dissatisfied } \\
\mathrm{n}(\%)\end{array}$ & $\begin{array}{l}\text { Nonresponse } \\
\mathrm{n}(\%)\end{array}$ \\
\hline $\begin{array}{l}\text { Midwife-led care for normal pregnancy } \\
\text { and childbirth }\end{array}$ & $14(34.1 \%)$ & $10(24.4 \%)$ & $12(29.3 \%)$ & $3(7.3 \%)$ & $1(2.4 \%)$ & $1(2.4 \%)$ \\
\hline The number of USG's time & $7(17.1 \%)$ & $3(7.3 \%)$ & $12(29.3 \%)$ & $16(39.0 \%)$ & $3(7.3 \%)$ & \\
\hline $\begin{array}{c}\text { Explanation about timing of } \\
\text { hospitalization }\end{array}$ & $8(19.5 \%)$ & $9(22.0 \%)$ & $9(22.0 \%)$ & $13(31.7 \%)$ & $2(4.9 \%)$ & \\
\hline Midwives show the evidence and data & $9(22.0 \%)$ & $11(26.8 \%)$ & $18(43.9 \%)$ & $1(2.4 \%)$ & $2(4.9 \%)$ & \\
\hline Diversity of midwives & $8(19.5 \%)$ & $10(24.4 \%)$ & $19(46.3 \%)$ & $3(7.3 \%)$ & $1(2.4 \%)$ & \\
\hline $\begin{array}{l}\text { Timing of the hospitalization, } \\
\text { (Mother can go to hospital, when } \\
\text { dilation is over } 4 \mathrm{~cm} \text { ) }\end{array}$ & $6(14.6 \%)$ & $6(14.6 \%)$ & $13(31.7 \%)$ & $8(19.5 \%)$ & $7(17.1 \%)$ & $1(2.4 \%)$ \\
\hline $\begin{array}{l}\text { Midwifery care for your complain about } \\
\text { labor pain }\end{array}$ & $9(22.0 \%)$ & $9(22.0 \%)$ & $11(26.8 \%)$ & $5(12.2 \%)$ & $5(12.2 \%)$ & $2(4.9 \%)$ \\
\hline $\begin{array}{c}\text { Selection of water birth and epidural } \\
\text { delivery }\end{array}$ & $30(73.2 \%)$ & $7(17.1 \%)$ & $2(4.9 \%)$ & $0(0 \%)$ & $1(2.4 \%)$ & $1(2.4 \%)$ \\
\hline Midwife-led care during childbirth & $14(34.1 \%)$ & $9(22.0 \%)$ & $13(31.7 \%)$ & $3(7.3 \%)$ & $1(2.4 \%)$ & $1(2.4 \%)$ \\
\hline Episiotomy and suturing by midwife & $10(24.4 \%)$ & $8(19.5 \%)$ & $14(34.1 \%)$ & $5(12.2 \%)$ & $2(4.9 \%)$ & $2(4.9 \%)$ \\
\hline $\begin{array}{l}\text { No charge of perinatal clinic expense } \\
\text { and childbirth expense }\end{array}$ & $38(92.8 \%)$ & $1(2.4 \%)$ & $1(2.4 \%)$ & $0(0 \%)$ & $1(2.4 \%)$ & \\
\hline Breastfeeding support for mothers & $12(29.3 \%)$ & $13(31.7 \%)$ & $6(14.6 \%)$ & $6(14.6 \%)$ & $4(9.8 \%)$ & \\
\hline Medical Interpreting service in NHS & $4(9.8 \%)$ & $2(4.9 \%)$ & $8(19.5 \%)$ & $0(0 \%)$ & $1(2.4 \%)$ & $26(63.4)$ \\
\hline Parenting Class & $11(26.8 \%)$ & $13(31.7 \%)$ & $8(19.5 \%)$ & $0(\%)$ & $2(4.9 \%)$ & $7(17.1 \%)$ \\
\hline $\begin{array}{c}\text { Easy acquisition of paternal leave in the } \\
\text { UK }\end{array}$ & $23(56.1 \%)$ & $0(0 \%)$ & $5(12.2 \%)$ & $0(0 \%)$ & $2(4.9 \%)$ & $11(26.8 \%)$ \\
\hline Health guidance by midwife & $11(26.8 \%)$ & $9(22.0 \%)$ & $6(14.6 \%)$ & $1(2.4 \%)$ & $1(2.4 \%)$ & $13(31.7 \%)$ \\
\hline Home visit by community midwife & $27(65.9 \%)$ & $8(19.5 \%)$ & $1(2.4 \%)$ & $2(4.9 \%)$ & $1(2.4 \%)$ & $2(4.9 \%)$ \\
\hline
\end{tabular}

\subsection{Satisfaction of Health Care Service (Table 4)}

Regarding health care service, they were satisfied with "no charge of perinatal clinic expense and childbirth expense," "selection of water birth and epidural delivery," "midwife-led care for normal pregnancy and childbirth," "midwife-led care during childbirth," "easy acquisition of paternal leave in the UK," and "home visit by community midwife." They were not satisfied with "the number of USG's time," "explanation about timing of hospitalization" and "timing of the hospitalization (Mother can go to hospital, when dilation is over $4 \mathrm{~cm})$."

\subsection{The Advisers and the Source of Information during Pregnancy, Childbirth, and Postpartum (Table 5)}

Regarding the advisers for Japanese residents in the UK, the percentages of "Japanese friends residing in the UK," "husband/partner," "family in Japan," "foreign friends were living in the UK," "midwife," "Japanese friends were living in Japan," and "others" were $23.5 \%, 21.0 \%$, $17.7 \%, 15.1 \%, 10.9 \%, 10.1 \%$, and $2.7 \%$, respectively. Regarding the source of information for Japanese residents in the UK, the percentages of "Internet information written in Japanese," "Japanese friends who were living and had experienced childbirth in the UK ," "Internet information written in English," "Books on childcare written in Japanese," "Foreign friends who were living and had experienced childbirth in the UK," "Japanese friends who were living and had experienced childbirth in the Japan," "Books on childcare written in English," "Japanese mothers' self-help group in the UK," and "others" were $20.3 \%, 19.0 \%, 14.9 \%, 12.8 \%, 10.2 \%$, $8.7 \%, 6.7 \% 4.7 \%$, and $2.7 \%$, respectively. 
Table 5. The advisers and the source of information during pregnancy, childbirth, and postpartum $(n=41)$

\begin{tabular}{|c|l|c|}
\hline \multirow{4}{*}{$\begin{array}{c}\text { The advisers } \\
\text { (M/A) }\end{array}$} & Japanese friends deciding in the UK & $26(23.5 \%)$ \\
\cline { 2 - 3 } & Husband/partner & $25(21.0 \%)$ \\
\cline { 2 - 3 } & Family in Japan & $21(17.7 \%)$ \\
\cline { 2 - 3 } & Foreign friends were living in the UK & $18(15.1 \%)$ \\
\cline { 2 - 3 } & Midwife & $13(10.9 \%)$ \\
\cline { 2 - 3 } $\begin{array}{c}\text { The source of } \\
\text { information } \\
\text { (M/A) }\end{array}$ & Japanese friends were living in Japan & $12(10.1 \%)$ \\
\cline { 2 - 3 } & Others & $2(1.7 \%)$ \\
\cline { 2 - 3 } & Internet information written in Japanese & $30(20.3 \%)$ \\
\cline { 2 - 3 } & Japanese friends who were living and had experienced childbirth in the UK & $28(19.0 \%)$ \\
\cline { 2 - 3 } & Internet information written in English & $22(14.9 \%)$ \\
\cline { 2 - 3 } & Joreign friends who had experienced childbirth in the UK & $19(12.8 \%)$ \\
\cline { 2 - 3 } & Book on childcare written in English & $15(10.2 \%)$ \\
\cline { 2 - 3 } & Japanese mothers' self-help group in the UK & $13(8.7 \%)$ \\
\cline { 2 - 3 } & Others & $10(6.7 \%)$ \\
\hline
\end{tabular}

\subsection{Scores of Self-Evaluation Scales on Pregnancy and Childbirth Experiences (Table 6)}

Table 6. Scores of self-evaluation scales on pregnancy and childbirth experiences

\begin{tabular}{|c|l|c|}
\hline $\begin{array}{l}\text { Self-evaluation of childbirth experience } \\
\text { scale (short version) }\end{array}$ & Mean \pm SD \\
\hline 1 & Labor coping score & $22.3 \pm 7.7(7-35)$ \\
\hline 2 & Trust to medical staff score & $16.0 \pm 6.0(5-24)$ \\
\hline 3 & Physiological childbirth progress score & $21.5 \pm 4.6(10-29)$ \\
\hline & Total score & $59.8 \pm 13.4(32-86)$ \\
\hline Maternal consciousness scale & $19.0 \pm 2.9(12-24)$ \\
\hline 1 & Positive feeling score & $11.7 \pm 3.1(16-18)$ \\
\hline 2 & Negative feeling score & $30.7 \pm 6.0(2-37)$ \\
\hline \multicolumn{2}{|l|}{ Total score } & $18.9 \pm 5.1(8-24)$ \\
\hline Couple-related scale & $25.2 \pm 2.5(20-30)$ \\
\hline \multicolumn{2}{|l}{ Total score } \\
\hline Cross-cultural Understanding & Total score \\
\hline
\end{tabular}

The total score of self-evaluation of childbirth experience scale (short version) was $59.8 \pm 13.4$ points (range, 32-86 points), and subscales were "labor coping ( $22.3 \pm 7.7$ points; range, $7-35$ points)," "trust to medical staff (16.0 \pm 6.0 points; range, 5-24 points)," and "physiological childbirth progress $(21.5 \pm 4.6$ points; range, $10-29$ points)." The "high labor coping" group was 20 , and the "low labor coping" group was 21, the "high trust to staff" group was 24, and the "low trust to staff" group was 17 , and the "high physiological progress" group was 24 , and the "low physiological progress" group was 17. The total score for maternal consciousness scale was
$30.7 \pm 6.0$ points (range, $25-37$ points), and the subscales were "the positive feeling (19.0 \pm 2.9 points; range, 12-24 points)" and "the negative feeling $(11.7 \pm 3.1$ points; range, 6-18 points)." The "high motherhood(positive)" group was 24, and the "low motherhood(positive)" group was 17. The "high motherhood(positive)" group was 21, and the "low motherhood(negative)" group was 20. The total score of couple-related scale was $18.9 \pm 5.1$ points (range, 8- 24 points). The "high relationship" group was 24 , and the "low relationship" group was 17. The total score of cross-cultural understanding scale was $25.2 \pm 2.5$ points (range, 20-30 points). The "high understanding" group was 19, and the "low understanding" group was 22 .

\subsection{Influence on Perinatal Clinic and Childbirth (Table 7)}

\subsubsection{Influence on Perinatal Clinics Satisfaction Factors}

The satisfaction with pre-natal clinic in intercultural "understanding" group were significantly higher than that in "not understanding" group $(\mathrm{P}<0.05)$.

\subsubsection{Influence on Childbirth Satisfaction Factors}

On the satisfaction with childbirth medical system "understanding" group was significantly higher than that in "not understanding" group $(\mathrm{P}<0.05)$, intercultural "understanding" group were significantly higher than that in "not understanding" group $(\mathrm{P}<0.01)$, childbirth experience "high trust to stuff" group were significantly higher than that in "low trust to stuff" group $(\mathrm{P}<0.001)$, and cross-cultural "high understanding" group was significantly higher than that in "low understanding" group $(\mathrm{P}<0.05)$. 
Table 7. Influence on perinatal clinic and childbirth $(\mathrm{n}=41)$

\begin{tabular}{|c|c|c|c|c|c|c|c|c|c|}
\hline & \multicolumn{3}{|c|}{$\begin{array}{l}\text { Perinatal clinic } \\
\text { satisfaction }\end{array}$} & \multirow[b]{2}{*}{$P$ Value } & & \multicolumn{3}{|c|}{ Childbirth satisfaction } & \multirow[b]{2}{*}{$P$ Value } \\
\hline & high & low & total & & & high & low & total & \\
\hline Medical system & & & & & Medical system & & & & \\
\hline Not understanding & 10 & 4 & 14 & \multirow{2}{*}{0.461} & Not understanding & 8 & 6 & 14 & \multirow{2}{*}{$0.020 *$} \\
\hline Understanding & 22 & 5 & 27 & & Understanding & 24 & 3 & 27 & \\
\hline total & 32 & 9 & 41 & & total & 32 & 9 & 41 & \\
\hline $\begin{array}{l}\text { Intercalutural } \\
\text { understanding }\end{array}$ & & & & & $\begin{array}{l}\text { Intercalutural } \\
\text { understanding }\end{array}$ & & & & \\
\hline Not understanding & 7 & 5 & 12 & \multirow{2}{*}{$0.050^{*}$} & Not understanding & 6 & 6 & 12 & \multirow{2}{*}{$0.005^{* *}$} \\
\hline Understanding & 25 & 4 & 29 & & Understanding & 26 & 3 & 29 & \\
\hline total & 32 & 9 & 41 & & total & 32 & 9 & 41 & \\
\hline Childbirth experience & & & & & Childbirth experience & & & & \\
\hline Low labor coping & 15 & 6 & 21 & \multirow{2}{*}{0.294} & Low labor coping & 14 & 7 & 21 & \multirow{2}{*}{0.071} \\
\hline High labor coping & 17 & 3 & 20 & & High labor coping & 18 & 2 & 20 & \\
\hline total & 32 & 9 & 41 & & total & 32 & 9 & 41 & \\
\hline Childbirth experience & & & & & Childbirth experience & & & & \\
\hline $\begin{array}{l}\text { Low trust to medical } \\
\text { staff }\end{array}$ & 13 & 6 & 19 & \multirow{2}{*}{0.837} & Low trust to staff & 9 & 8 & 17 & \multirow{2}{*}{$0.001 * * *$} \\
\hline $\begin{array}{l}\text { High trust to medical } \\
\text { staff }\end{array}$ & 19 & 3 & 22 & & High trust to staff & 23 & 1 & 24 & \\
\hline total & 32 & 9 & 41 & & total & 32 & 9 & 41 & \\
\hline Childbirth experience & & & & & Childbirth experience & & & & \\
\hline $\begin{array}{l}\text { Low physiological } \\
\text { childbirth progress }\end{array}$ & 13 & 4 & 17 & \multirow{2}{*}{0.116} & $\begin{array}{l}\text { Low physiological } \\
\text { childbirth progress }\end{array}$ & 14 & 5 & 19 & \multirow{2}{*}{0.530} \\
\hline $\begin{array}{l}\text { High physiological } \\
\text { childbirth progress }\end{array}$ & 19 & 5 & 24 & & $\begin{array}{l}\text { High physiological } \\
\text { childbirth progress }\end{array}$ & 18 & 4 & 22 & \\
\hline total & 32 & 9 & 41 & & total & 32 & 9 & 41 & \\
\hline $\begin{array}{c}\text { Maternal } \\
\text { consciousness } \\
\text { (Positive) } \\
\end{array}$ & & & & & $\begin{array}{c}\text { Maternal } \\
\text { consciousness } \\
\text { (Positive) } \\
\end{array}$ & & & & \\
\hline Low motherhood & 12 & 5 & 17 & \multirow{2}{*}{0.331} & Low motherhood & 13 & 4 & 17 & \multirow{2}{*}{0.837} \\
\hline High motherhood & 20 & 4 & 24 & & High motherhood & 19 & 5 & 24 & \\
\hline total & 32 & 9 & 41 & & total & 32 & 9 & 41 & \\
\hline $\begin{array}{c}\text { Maternal } \\
\text { consciousness } \\
\text { (Negative) } \\
\end{array}$ & & & & & $\begin{array}{c}\text { Maternal } \\
\text { consciousness } \\
\text { (Negative) } \\
\end{array}$ & & & & \\
\hline Low motherhood & 18 & 2 & 20 & \multirow{2}{*}{$0.071 \dagger$} & Low motherhood & 17 & 3 & 20 & \multirow{2}{*}{0.294} \\
\hline High motherhood & 14 & 7 & 21 & & High motherhood & 15 & 6 & 21 & \\
\hline total & 32 & 9 & 41 & & total & 32 & 9 & 41 & \\
\hline Couple-related & & & & \multirow{2}{*}{$0.082 \dagger$} & Couple-related & & & & \\
\hline Low relationship & 11 & 6 & 17 & & Low relationship & 12 & 5 & 17 & \multirow{2}{*}{0.331} \\
\hline High relationship & 21 & 3 & 24 & & High relationship & 20 & 4 & 24 & \\
\hline total & 32 & 9 & 41 & & total & 32 & 9 & 41 & \\
\hline $\begin{array}{l}\text { Cross-cultural } \\
\text { understanding }\end{array}$ & & & & & $\begin{array}{l}\text { Cross-cultural } \\
\text { understanding }\end{array}$ & & & & \\
\hline Low understanding & 16 & 6 & 22 & \multirow{2}{*}{0.376} & Low understanding & 20 & 2 & 22 & \multirow{2}{*}{$0.032 *$} \\
\hline High understanding & 16 & 3 & 19 & & High understanding & 12 & 7 & 19 & \\
\hline total & 32 & 9 & 41 & & total & 32 & 9 & 31 & \\
\hline
\end{tabular}

$\dagger \mathrm{P}<0.1, * \mathrm{P}<0.05, * * \mathrm{P}<0.01,{ }^{*} * \mathrm{P}<0.001$ 


\section{Discussion}

Regarding health care and health services provided, Japanese mothers were not satisfied with the examination by ultrasonography and explanation about timing of the hospitalization, but they were satisfied with the care provided by midwife, taking paternal leave, and home visiting service. Approximately $80 \%$ of Japanese mothers were satisfied with pre-natal clinics and childbirth in the UK. Intercultural understanding was related to satisfaction with pre-natal clinics, while trust to medical staff, intercultural understanding, medical system differences and cross-cultural understanding were related to the satisfaction with childbirth.

First, Japanese mothers residing in the UK understood well the medical health care system on pregnancy and childbirth and the access from GP to NHS. There are no significant differences in maternal statistics data on medical care standard between the UK and Japan[15]. Therefore, it was assumed that Japanese mothers hoped to stay in the UK and accepted pre-natal clinics in NHS. Regarding the communication and obtaining the information, many Japanese mothers had attended pre-natal clinics with husbands/partners. Although Japanese mothers can speak English at the daily communication level, they had trouble speaking medical level English. It was speculated that Japanese mothers could feel anxious on English communication at the hospital and communicated with the midwife through husbands/partners. Contrary to Japan, husbands/partners can take the acquisition and the use of paternal leave [16]. They consulted their husbands/partners, Japanese friends in the UK, and families in Japan, and also obtained the information about pregnancy and childbirth on the Internet and from Japanese friends in the UK. It seems likely that they may feel comfortable on consultation using the Japanese language, mother's native tongue. Regarding the utilization of Japanese mothers child-rearing group in the UK (NAKAYOSHI-KAI), they attended child-rearing events more after childbirth than during pregnancy. NAKAYOSHI-KAI might be a place of child care consultation or valuable interchange in Japanese. They chose a variety of delivery modes such as epidural birth, water birth, and home birth. Rate of epidural birth was $6.1 \%$ (2016) [17], and the extra charge for epidural anesthesia is required in Japan, while in the UK, there is no extra payment for epidural birth. Moreover, since the length of postpartum hospitalization in the UK is short, they have to start their child-rearing immediately after they are discharged from the hospital. Therefore, they may choose epidural birth to conserve their health for child-rearing at home.

Regarding Japanese maternity custom, Japanese mothers wear the maternity belt (FUKUTAI) on the 'Day of the Dog' at approximately 16 weeks of gestation and pray for safe childbirth during pregnancy. Although
Japanese mothers residing in the UK hope to perform a ceremony of wearing a maternity belt (FUKUTAI), they could not perform it. On the contrary, there is another custom, that is, keeping the umbilical cord, which falls off from a newborn baby. The enforcement rate was significantly higher in keeping the umbilical cord compared to wearing the maternity belt. Because the UK's length of hospitalization is shorter than that of Japan, without manual instruction, mothers can easily keep the baby's umbilical cord, which fell off at home.

Regarding health care and health services to Japanese mothers residing in the UK, they felt that ultrasonography and the explanation on the timing of the hospitalization at pre-natal clinics were insufficient. In the UK, midwife-led care is provided for a normal pregnant woman. The examination by ultrasonography is performed twice during the gestational period. However, in Japan, doctorand midwife-led care is provided in the clinic and hospital, and ultrasonography is performed every time during pre-natal clinics. Ultrasonography was enforced as a screening method that assesses the well-being of the mother and fetus and considered a tool that promotes the attachment of the mother to the fetus at pre-natal clinics. Therefore, Japanese mothers residing in the UK might have dissatisfaction about the examination by ultrasonography. Japanese mothers had anxiety on the timing of hospitalization after the onset of labor. They can be admitted at the hospital with cervical canal dilation greater than $4 \mathrm{~cm}$ [18]. It was suggested that Japanese mothers residing in the UK might feel discomfort after the onset of labor and they have to endure labor pains in a foreign country. The average duration of hospitalization after childbirth was 6 days for vaginal childbirth at a hospital, a clinic, and a birth home in Japan [19]. In the UK, mothers who underwent vaginal childbirth can leave the hospital 6 hours after childbirth [20]. It was thought that they were satisfied with the UK's length of hospitalization, even if the length of stay in the hospital is much shorter than that of Japan. Because they could take home visiting service and postpartum care by a community midwife [21], Japanese mothers were highly satisfied with the health care from pregnancy to childbirth provided by the midwife. The midwife is beside Japanese mothers during labor and childbirth based on the one-by-one care system [22]; therefore, Japanese mothers could build a good relationship with the assigned midwife. This might have contributed to the high satisfaction on Japanese mothers' childbirth experience.

Considering the factors related to satisfaction on pregnancy and childbirth experience in Japanese mothers residing in the UK, intercultural understanding was indicated in pre-natal clinics, while trust to medical staff, and intercultural understanding at the hospital, understanding a medical system and cross-cultural understanding were indicated in childbirth. It was estimated that mothers who were advancing toward 
intercultural understanding could be satisfied with pre-natal clinics and childbirth in the UK. Mothers with intercultural understanding also recognized the differences in health-care system and medical system between Japan and the UK. Regarding economics, the NHS is a system where members can visit a hospital without paying, although a constant rate from a prescription and dental practice in some areas has to be paid [23]. In Japan, mothers must bear ultrasonography, blood tests, and epidural childbirth costs. The less financial burden in the UK could contribute to the high satisfaction on childbirth for Japanese mothers.

From pregnancy to childbirth for Japanese mothers residing in the UK, daily communication in English was high; hence, medical systems were significantly understood and the satisfaction was high in intercultural understanding. Regardless of communicative competence, I created a leaflet so that Japanese mothers residing in the UK can easily access the British medical system and obstetrical service through the Internet, and suggested that providing sufficient information is effective in the future. Regardless of English level communication and medical level English, it is necessary to take the aid package so that experiences of Japanese mothers residing in the UK experiencing pregnancy and childbirth are better.

It is essential that they will get the information by NHS's health professionals provide leaflets containing information about the British medical system and health care services to Japanese mothers residing in the UK. We have to make the leaflets base on our research.

\section{Conclusions}

In conclusion, we demonstrated that most Japanese mothers residing in the UK utilized NHS and independently chose a variety of childbirth modes. Although they wished to wear the maternity belt (FUKUTAI) and keep their baby's umbilical cord, which are Japanese maternity customs, they could not perform such customs. Regarding health care and health services provided, Japanese mothers were not satisfied with the examination performed by ultrasonography and explanation on the hospitalization. However, they were satisfied with the care provided by the midwife, taking paternal leave, and home visiting service. Approximately $80 \%$ of Japanese mothers were satisfied with pre-natal clinics and childbirth in the UK. Intercultural understanding at the hospital was related to satisfaction of pre-natal clinics, while trust to medical staff, intercultural understanding, understanding about medical system and cross-cultural understanding were related to the satisfaction of childbirth.

\section{Acknowledgements}

The author wishes to thank Japanese mothers residing in the UK for her help in this study.

\section{REFERENCES}

[1] Annual Report of Statistics on Japanese Nationals Overseas, Online available: https://www.mofa.go.jp/mofaj/files/0003 68753.pdf

[2] Vital Statistics in Japan, 2017, Online available: https://ww w.mhlw.go.jp/toukei/saikin/hw/jinkou/kakutei17/index.ht $\mathrm{ml}$

[3] H. Taniguchi, Over an early discharge 24 hour in after giving birth in America from field study in Hawaii, Japanese Journal of Maternal Health, Vol.40, No.2, 356-357, 1999.

[4] H. Taniguchi, G. Baruffi, Childbirth overseas: The experience of Japanese women in Hawaii, Nursing \& Health Sciences, Vol.9, No.2, 90-95, 2007.

[5] H. Taniguchi, L. Magnussen, Expatriate Japanese women's growth and transformation through childbirth in Hawaii, USA, Nursing \& Health Sciences, Vol.11, No.3, 271-276, 2009.

[6] Orito M., Kojima T., Nakamura Y., Ratio of local delivery of overseas Japanese residents abroad, Japanese Journal of Maternal Health, Vol.42, No.4, 765-772, 2001.

[7] S. Tsugihara, N. Sasaki, H. Miyahara, Factors influencing self-evaluations of the childbirth experience, Health Science Research, Vol.29, 9-16, 2017.

[8] Y. Tokiwa, S. Imazeki, Design of self-evaluation scale for experience of delivery and study of its reliability and validity, Journal of Japan Academy of Nursing Science, Vol.20, No.1, 1-9, 2000

[9] M. Ohinata, Maternal research, Kawashima Shoten, Japan, 135-169, 1988

[10] M. Ohinata, Maternal consciousness scale, Collection of psychology standard measurement III, Saiensu-sha, Japan, 103-106, 2009.

[11] K. Moroi, Couple-related scale, Collection of psychology standard measurement II, Saiensu-sha, Japan, 149-152, 2011.

[12] T. Kamiyama, Marital relationships of married couples raising children with discrepant family role concepts, The Japanese Journal of Developmental Psychology, Vol.24, No.3, 238-249, 2013.

[13] K. Suzuki, ISU2000, Collection of psychology standard measurement IV, Saiensu-sha, Japan, 101-103, 2009.

[14] J. Numata, Japanese university students' consciousness of intercultural understanding: A study of factors concerning intercultural understanding, Social Science Review, Vol.91, 169-186, 2010.

[15] Maternal and Child Health Statistics of Japan, Mothers' and Childrens' Health and Welfare Association, 2017.

[16] British Childcare Leave System and Coexistence System, The Japan Institute for Labour Policy and Training, Online 
available: https://www.jil.go.jp/foreign/labor_system/2018 /12/uk.html

[17] Japan Society of Obstetrics and Gynecology, Survey on parturition, 2017.

[18] National Health Service, Online available:https://www.nhs. uk/conditions/pregnancy-and-baby/what-happens-during-la bour-and-birth/

[19] Y. Katsukawa, K. Sakanashi, M. Usui, M. Kobayashi, Condition of the present conditions and the length of stay shortening of the postpartum hospitalization-From the result of the national investigation, The Japanese Journal of Midwives, 64(4), 302-306, 2010.

[20] K. Sakanashi, Y. Katsukawa, M. Usui, M. Nabeta, A. Ohga, S. Nagai, Preference regarding conditions for postpartum early discharge and support system: View of medical profession, Yokohama Journal of Nursing, 4(1), 71-77, 2011.

[21] J. Garcia, M. Renfrew, S. Marchant, Postnatal home visiting by midwives, Midwifery, Vol.10, 40-43, 1994.

[22] National Institute for Health and Care Excellence, Health and social care directorate quality standard consultation summary report, Online available: https://www.nice.org.uk /guidance/qs105/documents/consultation-summary-report

[23] Y. Hibota, British medical system and Japan, Clinic All-Round, Vol.56, No.12, 3158-3162, 2007. 